\title{
Latent inhibition of the rabbit's nictitating membrane response: Summation tests for active inhibition as a function of number of CS preexposures*
}

\author{
PAUL R. SOLOMON, A. CRAIG LOHR, and JOHN W. MOORE \\ University of Massachusetts, Amherst, Massachusetts 01002
}

\begin{abstract}
Rabbits received classical conditioning of the nictitating membrane response to a light CS. Experimental animals then received 18, 36, 118, or 354 nonreinforced tone presentations followed by summation tests for active inhibition in which the tone was compounded with the light. Control animals sat restrained in the conditioning chambers for periods of time corresponding to the experimental animals, but did not experience the tone between initial conditioning to the light and the summation test phase. The degree to which addition of the tone depressed conditioned responding to the light was essentially the same for experimental and control groups, thereby negating the possibility that the tone possessed active or conditioned inhibitory properties.
\end{abstract}

Lubow and Moore (1959) coined the term "latent inhibition" in reference to the fact that as few as $15-20$ nonreinforced CS presentations can retard subsequent conditioning. Most available evidence, as reviewed by Lubow (1973), suggests that CS preexposure produces attentional deficits which must be overcome in order for conditioning to occur. Thus, nonreinforced CS presentation prior to conditioning does not produce an active inhibitor in the sense of conditioned inhibition, but results instead in a "tuning out" of the CS. This conclusion is consistent with the Wagner-Rescorla (1972) model in that CS preexposures do not have an excitatory frame of reference by which the stimulus can take on negative value. Instead, CS preexposures moves the CS toward neutrality or zero value through loss of salience.

Confirmation of this last point for the rabbit eye blink preparation has been provided by Reiss and Wagner (1972). Using a tone, flashing light, and vibratory stimuli, these investigators compared the rate of conditioning to CSs which had 1380 preexposures (A) or only 12 preexposures (B) with that of a novel cue (C). Conditioning to $\mathrm{A}$ and $\mathrm{B}$ were significantly retarded compared with $\mathrm{C}$, with $\mathrm{A}$ yielding the slowest rate of conditioning. A second experiment contrasted A (1380 exposures) with B (12 preexposures) in combined-cue summation tests with $C$ (120 conditioning trials). While the addition of $\mathrm{A}$ or $\mathrm{B}$ to $\mathrm{C}$ produced a decrease in conditioned responding, $B$ produced the greater reduction in CR strength. Since B, with only 12 preexposures, had a greater decremental effect than A, with 1380 preexposures, the evidence favors an attention decrement or loss-of-salience interpretation.

Unfortunately, one cannot judge whether the

*This research was supported by NSF grant GB-24557 to the third author. Requests for reprints should be addressed to John W. Moore, Department of Psychology, Middlesex House, University of Massachusetts, Amherst, Massachusetts, 01002. observed inhibitory summation, especially with B, was due to external inhibition, generalization decrement, or to some other factor related to the novelty of the test compound, on the one hand, or whether preexposure actually endowed the CSs with active inhibition, on the other. As few as 12 preexposures (Stimulus B) might have produced active inhibition (negative value) which dissipated only after many more preexposures. What was needed in the Reiss and Wagner study to separate any active or conditioned inhibitory effects of preexposure from those of external inhibition was a summation test involving $\mathrm{C}$ and novel cue. Therefore, while the Reiss and Wagner (1972) study demonstrated that 1380 preexposures resulted in a loss of salience when contrasted with 12 preexposures, their data do not rule out the possibility that 12 preexposures produced active inhibition. Thus, it is possible that the inhibitory summation observed in a combined-cue test given 12 preexposures to $\mathrm{C}$ would exceed that observed with a stimulus which had never been preexposed.

The purpose of the present experiment was to test the hypothesis that preexposure endows the CS with active inhibitory properties, but that these properties can be masked or reversed with a large number of CS preexposures. This hypothesis implies that inhibitory summation is a nonmonotonic function of number of CS preexposures, first increasing and then decreasing. Accordingly, the present experiment investigated inhibitory summation as a function of number of CS preexposures.

\section{METHOD}

\section{Subjects and Apparatus}

The Ss were 64 naive white New Zealand rabbits maintained on food and water ad lib for the duration of the experiment. The apparatus and methods used to condition the rabbits nicititating membrane response was basically that described by Gromezano 
Fig. 1. Results of summation testing: Mean percentage of CRs to light $(L)$ and light plus tone (LT) as a function of number of tone preexposures.

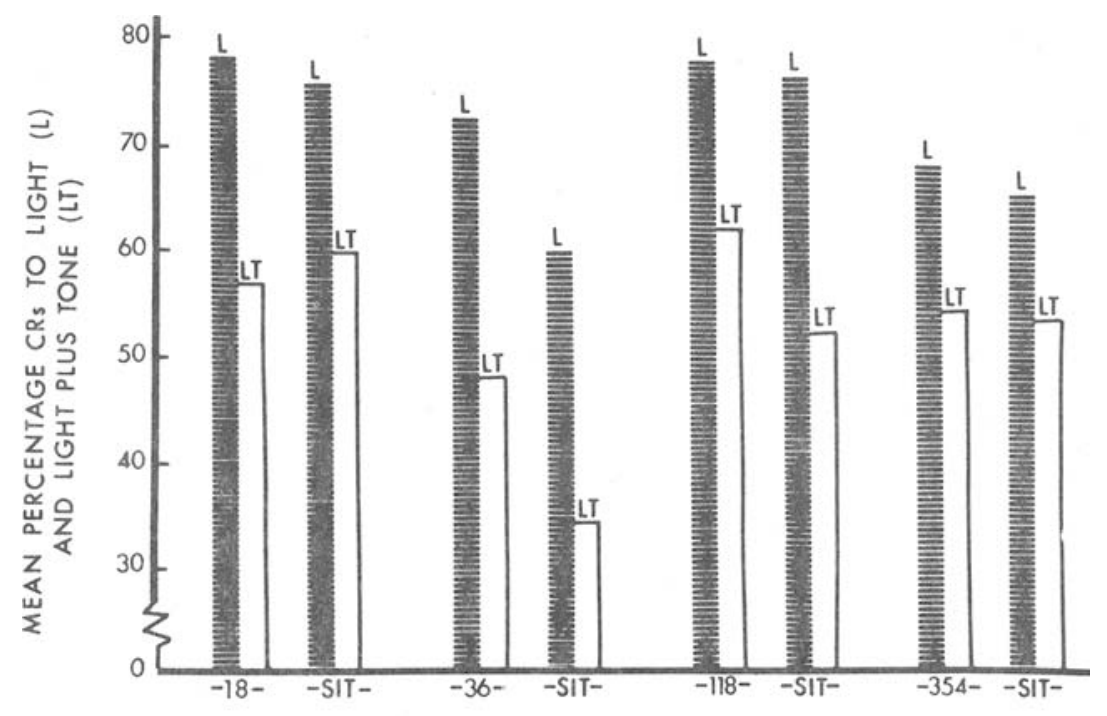

NUMBER OF PREEXPOSURES

(1966) and Marchant, Mis, and Moore (1972). The UCS was a 2-mA ac shock of $50 \mathrm{msec}$, administered through two stainless steel wound clips implanted into the skin, one placed just below the right eye and one placed lateral and in back of the right eye. The preexposed CS in this experiment was a $1200-\mathrm{Hz}$ tone of $85 \mathrm{~dB}$ SPL.

\section{Design and Procedure}

On the day following suturing and adaptation to restraint, Ss received 5 days (100 trials/day to a criterion of $90 \% \mathrm{CRs}$ ) of acquisition to a light CS at an ISI of .5 sec and utilizing a $2-\mathrm{mA}$ ac infraorbital shock as the UCS. Animals were matched on the basis of rate of acquisition, one member of the pair receiving tone alone presentations. The other animal served as a yoked control, experiencing the same handling, restraint, etc., but no tone preexposures. There was a 4-day interval between the last conditioning session and the first day of summation testing for all animals. Four groups of eight rabbits received 18, 36, 118, or 354 preexposures to the tone as follows: (a) Rabbits in the 18 and 36 exposure conditions remained in their home cages until the fourth day following acquisition to the light, at which time they received 18 or 36 tone alone trials at an ITI of $30 \mathrm{sec}$ followed without interruption by 25 light alone and 25 light plus tone summation test trials. The eight matched control animals received exactly the same treatment except that the 18 or 36 preexposures to the tone were omitted. (b) Animals in the 118 preexposure condition received 100 tone alone presentations on the third day following acquisition to the light and 18 additional tone trials prior to the summation test on Day 4. Their matched "sit" controls received exactly the same treatment with respect to handling and restraint, but the tone was withheld until summation testing. (c) The 354 group received 100 tones per day until Day 4, at which time they received 54 tone presentations followed by the same series of 50 summation test trials employed in the other experimental conditions. All groups received an additional series of 100 summation test trials (50 light alone and 50 light plus tone) on Day 5 following light acquisition. This series was preceded by 15 reinforced trials to the light alone.

\section{RESULTS AND DISCUSSION}

Inspection of Fig. 1 indicates only slight support for the hypothesis that the summation effect increases then decreases as a function of number of preexposures. The mean difference scores (\% CRs to light-\% CRs to light plus tone) were $21.4,24.7,15.7$, and 13.9 for 18,36 , 118 , and 354 preexposures, respectively. However, the corresponding set of mean difference scores for the matched "sit" controls were 15.9, 25.6, 23.9, and 11.9. Since the control animals show a similar pattern of summation effects as a function of "sitting" time in the conditioning apparatus, there is little support for the notion that a comparatively small number of tone preexposures would produce an active inhibitor.

Analyses of variance of the summation data in Fig. 1, as represented by a 2 by 4 factorial layout (4 levels of number of preexposures by preexposed vs "sit" controls), were carried out on two measures: (a) the difference in number of CRs between light alone and light plus tone trials, and (b) the "suppression ratio" computed by dividing the number of CRs to the light alone by the total number of CRs. Neither main effect nor the interaction between the two principal factors of the design contributed significantly to either measure of inhibitory potential of the tone. Consequently, there was no solid evidence of active inhibitory properties as a result of preexposures to the tone over the range (18-354) of preexposures tested in this experiment. These data provide additional support for the conclusion of Reiss and Wagner (1972) that latent inhibition of the rabbit's conditioned eye blink does not result from the development of active inhibition.

\section{REFERENCES}

Gormezano, I. Classical Conditioning. In J. B. Sidowski (Ed.) Experimental methods and instrumentation in psychology. New York: McGraw-Hill, 1966.

Lubow, R. E. Latent inhibition. Psychological Bulletin, 1973, $79,398-407$. 
Lubow, R. E., \& Moore, A. U. Latent inhibition: The effect of non-reinforced preexposure to the conditioned stimulus. Journal of Comparative \& Physiological Psychology, 1959, 52, 416-419.

Marchant, H. G., III, Mis, F. W., \& Moore, J. W. Conditioned inhibition of the rabbit's nictitating membrane response. Journal of Experimental Psychology, 1972, 95, 408-411.

Reiss, S., \& Wagner, A. R. CS habituation produces a "latent inhibition effect", but no active "conditioned inhibiton."
Learning \& Motivation, 1972, 3, 237-245.

Wagner, A. R \& Rescorla R. A. Inhibition in Pavlovian conditioning: application of a theory. In R. A. Boakes and M. S. Halliday (Eds.), Inhibition and learning. London: Academic Press, 1972.

(Received for publication August 29, 1974.)

\title{
Ordered recall of sounds and words in short-term memory*
}

\author{
EDWARD J. ROWE \\ Memorial University of Newfoundland, St. John's, Newfoundland, Canada
}

\begin{abstract}
Ordered recall of 7-item sequences of sounds and words was compared in two experiments. Bow-shaped serial position curves were found for both types of sequences, but more errors occurred with sounds at all serial positions. This inferior recall of sounds was independent of whether a verbal (Experiment I) or nonverbal (Experiment II) response procedure was used. The results confirm the superiority of verbal memory processes in the retention of order information.
\end{abstract}

Several recent experiments have demonstrated the importance of auditory-verbal memory processes in the retention of order information (e.g., del Castillo \& Gumenik, 1972; Paivio \& Csapo, 1969). These studies have compared serial recall or reconstruction of visual stimuli as a function of the availability of appropriate verbal labels, and have found better retention in cases where the items can be named by the Ss during presentation. Paivio (1971) interpreted such data to mean that the verbal memory code, being functionally linked to the auditory sensory modality, is specialized for retaining order informaton while the visual imagery code is not. This was advanced as one distinction between imagery and verbal processes.

A firmer case for this distinction can be made if the operation of verbal and nonverbal memory codes is contrasted independently of modality differences, e.g., if the comparison is restricted to the auditory modality alone. Philipchalk and Rowe (1971) reported an initial attempt in this direction. They compared retention of lists of short environmental sounds with their verbal labels in multitrial free and serial recall. Both kinds of items were recalled equally well in free recall but, in agreement with the hypothesized distinction between imagery and verbal processing modes, the words

*This researcn was supported by Grant A8580 from the National Reserach Council of Canada. Gordon Rowe and Madonna Tracey assisted in the data collection and analysis. Requests for reprints should be sent to the author at the Department of Psychology, Memorial University of New foundland, St. John's, Newfoundland, Canada A1C 5S7. consistently surpassed the sound across the five trials of serial recall. Even though the sounds could be named at presentation, it was assumed that the verbal code played a greater role in retention of the words, thus contributing to their more efficient serial ordering.

There were, however, certain difficulties inherent in the methodology of the Philipchalk and Rowe (1971) experiment which detract from an unambiguous interpretation of the results. For one thing, the interitem intervals were unequal for the sound and word lists, being $1 \mathrm{sec}$ for sounds but $5 \mathrm{sec}$ for words. This difference was unavoidable in constructing lists of comparable presentation rate, since the sounds averaged $5.4 \mathrm{sec}$, and the words $1 \mathrm{sec}$, in length. However, it is possible that the longer blank time between words facilitated their serial recall compared to sounds by allowing a greater opportunity for rehearsal of prior items within the list. Ss' proclivities toward rehearsal in memory tasks is well known, and cumulative rehearsal seems to be especially preferred as a strategy when ordered recall is required (Corballis, 1969). Given the positive influence of rehearsal on recall, the possible effect of different interitem intervals on the previous results cannot be discounted. The first experiment reported here was designed to remedy this shortcoming and provide a more stringent test of the difference between sounds and words in a serial recall task.

A further difficulty with the previous experiment involves the recall procedure. Recall was always verbal, i.e., the Ss wrote down the words or the names of the sounds, and the enhanced serial recall of the word lists 